EESTI NSV TEADUSTE AKADEEMIA TOIMETISED. KEEMIA

ИЗВЕСТИЯ АКАДЕМИИ НАУК ЭСТОНСКОП ССР. ХИМИЯ

PROCEEDINGS OF THE ACADEMY OF SCIENCES OF THE ESTONIAN SSR. CHEMISTRY

$1985,34,2$

удК 553.983:543.8

К. УРОВ, В.ВЫСОЦКАЯ, Д. ДРОБОТ

\title{
ИССЛЕДОВАНИЕ ОРГАНИЧЕСКОГО ВЕЩЕСТВА БЫВШИХ ГОРЮЧИХ СЛАНЦЕВ (ДРЕВНИЕ ГРАФИТОИДНЫЕ СЛАНЦЫ ВОСТОЧНОЙ СИБИРИ)
}

\author{
(Представил О. Эйзен)
}

Высокометаморфизованные графитоидные сланцы, органическое вещество (OB) которых, несмотря на сапропелевый исходный материал, практически потеряло способность генерировать жидкие органические продукты при термической деструкции, не могут классифицироваться как истинные горючие сланцы $\left[{ }^{1-3}\right]$. Вместе с тем, в плане изучения геохимических аспектов эволюции этого вида каустобиолитов, они представляют значительный интерес.

В настоящей работе приведены результаты изучения четырех образцов верхнерифейского возраста, отобранных в пределах Патомского нагорья и Прибайкальского палеопрогиба (Иркутская обл.): черного сланца олхинской свиты из обнажений по р. Правая Ушаковка (обр. 1), углистого черного сланца качергатской свиты с верховьев р. Правый Улькан (обр. 2), темно-серого аргиллита олхинской свиты из скв. 2 Космической площади (обр. 3) и углеродсодержащего кварцевого сланца валюхтинской свиты Сухоложского района (обр. 4). В процессе геологического развития бассейнов седиментации указанные отложения испытали погружение на глубины до 4 км (обр. 3), 5,5-6 км (обр. 1, 2) и $7-7,5$ км (обр. 4). Катагенетическая преобразованность ОВ в них достигает отощенно-спекающейся (обр. 3), полуантрацитовой (обр. $1,2)$ и антрацитовой (обр. 4) стадий.

Во избежание артефактов куски сланцев перед измельчением промывали диэтиловым эфиром в целях удаления с их поверхности возможных загрязнений. Измельченный в фарфоровой шаровой мельнице до 0,08 мм сланец обрабатывали $10 \%$-ной соляной кислотой, затем промытый водой и высушенный в вакууме материал экстрагировали последовательно смесью бензола и метилового спирта $(3: 1)$ и диэтиловым эфиром; в дальнейшем экстракты объединяли. Кислотные соединения выделяли из битумоидов 0,5 н. спиртовым раствором гидроокиси калия при кипячении. Нейтральную часть битумоидов разделяли на групповые компоненты методом тонкослойной хроматографии по методике [ $\left.{ }^{4}\right]$ на силикагеле; элюент - н-гексан. Выделенные группы соединений анализировали газохроматографически (кислоты - после метилирования диазометаном) на колонках различной полярности. Инфракрасные спектры снимали на приборе UR-10 в кюветах из бромистого калия. Полукоксование дебитумоидированных образцов проводили по ГОСТу 3168-66 в ретортах на 50 и 500 г сланца. В ряде случаев породу предварительно обогащали смесью концентрированных соляной и плавиковой кислот по [5]. Газообразные продукты анализировали газохроматографически на колонках с молекулярными ситами СaA и со скваланом в качестве неподвижной жидкой фазы. 


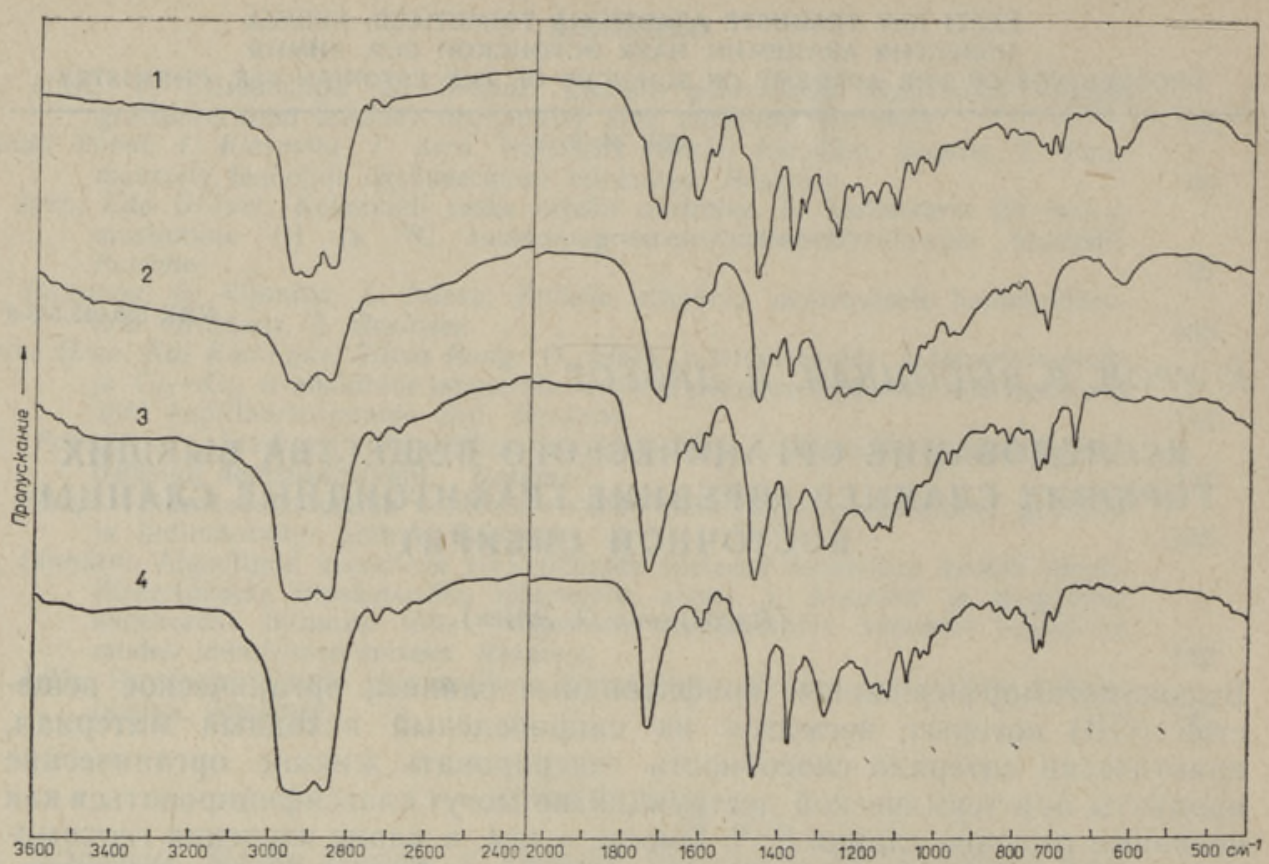

Рнс. 1. Инфракрасные спектры битумондов (цифры указывают номер образца сланца здесь и далее).

Наибольшее количество ОВ установлено в обр. 2 (табл. 1). Вследствие преимущественно некарбонатного характера минеральной части сланцев и искажения результатов анализа присутствием конституционной воды алюмосиликатов найденное количество условной органической массы лишь весьма приближенно соответствует истинному содержанию в них ОВ. Более показательны в этом плане данные о выходе битумоидов в расчете на сравнительно точно определяемый органический углерод. Как показали исследования, в любом случае их содержание примерно на порядок ниже среднего, чем в горючих сланцах, не подвергшихся глубоким преобразованиям. Очевидно, ОВ графитоидных сланцев в течение своей геологической истории потеряло основную массу подвижных органических соединений; битумоиды указанных пород следовало бы рассматривать как остаточные.

Однако инфракрасные спектры полученных экстрактов (рис. 1) заметно отличаются от типовых спектров остаточных битумоидов, но приближаются к спектрам синбитумоидов, лишенных или почти не содержащих миграционноспособных компонентов [6]. Лишь растворимая часть $\mathrm{OB}$ обр. 1 имеет по спектроскопическим характеристикам определенное сходство со смешанными битумоидами, хотя по количеству в расчете на ОВ отстоит от них далеко.

Правда, от типичных автохтонных битумоидов малопревращенных горючих сланцев исследовавшиеся экстракты отличаются большей величиной атомного отношения $\mathrm{H} / \mathrm{C}$ и меньшим (кроме обр. 2) содержанием гетероатомов (табл. $2 *$ ) и гетероатомных соединений (табл. 3). С другой стороны, содержание ароматических углеводородов (УВ), свидетелей термической трансформированности ОВ, в них относительно низкое. Для сравнения отметим, что УВ битумоида верхнедевонского сланца Селенняхского поднятия Северо-Восточной Якутии, достигшего главной

* Данные табл. 2 подтверждают наблюдения [ $\left.{ }^{7}\right]$ о том, что эфир обладает повышенной по сравнению со спиртобензолом способностью извлекать УВ. 
Характеристика исследовавшихся сланцев, вес. \%

\begin{tabular}{|c|c|c|c|c|}
\hline \multirow{2}{*}{ Показатель } & \multicolumn{4}{|c|}{ Номер образца сланца } \\
\hline & 1 & 2 & 3 & 4 \\
\hline $\begin{array}{l}\text { Влага аналитическая } \\
\text { Зола } A^{\mathrm{c}} \\
\text { Углекислота карбонатов }\left(\mathrm{CO}_{2}\right)_{\text {с }} \text { карб } \\
\text { Условная органичекая масса } \\
{\left[100-A^{\mathrm{c}}-\left(\mathrm{CO}_{2}\right)^{\mathrm{c}} \text { карб }\right]} \\
\text { Сера общая } \\
\text { Углерод общий } \\
\text { Углерод органическнй } \\
\text { Выход суммарного битумоида: } \\
\text { на условнуюо органическую массу } \\
\text { на органический углерод }\end{array}$ & $\begin{array}{r}1,4 \\
94,1 \\
0,9 \\
5,0 \\
1,0 \\
2,79 \\
2,55 \\
\\
0,24 \\
0,47\end{array}$ & $\begin{array}{c}1,0 \\
82,3 \\
1,3 \\
16,4 \\
11,5 \\
13,45 \\
13,10 \\
\\
0,014 \\
0,018\end{array}$ & $\begin{array}{r}0,6 \\
94,2 \\
1,6 \\
4,2 \\
1,3 \\
1,93 \\
1,49 \\
0,24 \\
0,68\end{array}$ & $\begin{array}{r}0,1 \\
89,5 \\
6,3 \\
4,2 \\
1,8 \\
2,51 \\
0,79 \\
0,11 \\
0,58\end{array}$ \\
\hline
\end{tabular}

Таблица 2

Элементный состав битумоидов

\begin{tabular}{|c|c|c|c|c|c|}
\hline \multirow[b]{2}{*}{ Характер битумонда } & \multirow[b]{2}{*}{$\begin{array}{l}\text { Номер } \\
\text { образца } \\
\text { сланца }\end{array}$} & \multicolumn{3}{|c|}{ Содержание, вес. \% } & \multirow[b]{2}{*}{$\begin{array}{l}\text { Атом- } \\
\text { ное от- } \\
\text { ношение } \\
\text { Н/C }\end{array}$} \\
\hline & & Углерод & Водород & $\begin{array}{l}\text { Гетеро- } \\
\text { атомы } \\
\text { (по раз- } \\
\text { ности) }\end{array}$ & \\
\hline $\begin{array}{c}\text { Бензолметанольный } \\
\text { " } \\
\text { Эфирный } \\
\text { " }\end{array}$ & $\begin{array}{l}1 \\
2 \\
3 \\
4 \\
1 \\
2\end{array}$ & $\begin{array}{l}84,0 \\
74,7 \\
81,0 \\
84,7 \\
86,3 \\
81,8\end{array}$ & $\begin{array}{l}12,7 \\
11,4 \\
12,0 \\
12,7 \\
12,8 \\
12,5\end{array}$ & $\begin{array}{r}3,3 \\
13,9 \\
7,0 \\
2,6 \\
0,9 \\
5,7\end{array}$ & $\begin{array}{l}1,81 \\
1,83 \\
1,78 \\
1,80 \\
1,78 \\
1,83\end{array}$ \\
\hline
\end{tabular}

таблица 3

Групповой химический состав суммарных битумоидов, вес. \%

\begin{tabular}{l|r|r|r|r}
\hline \multirow{2}{*}{ Компонент } & \multicolumn{4}{|c}{ Номер образца сланца } \\
\cline { 2 - 5 } & 1 & 2 & 3 & 4 \\
\hline & & & & \\
Углеводороды - всего & 55,3 & 26,5 & 40,5 & 56,4 \\
неароматические & 47,2 & 12,5 & 32,7 & 43,0 \\
моноциклические ароматические & 1,9 & 10,9 & 1,1 & 8,9 \\
конденсированные ароматические & 6,2 & 3,1 & 6,7 & 4,5 \\
Нейтральные гетероатомные соединения & 10,5 & 11,7 & 12,2 & 11,6 \\
Кислотные соединения & 34,2 & 61,8 & 47,3 & 32,0 \\
эфирорастворимые & 21,3 & 58,9 & 38,7 & 16,7 \\
& & & &
\end{tabular}

зоны нефтеобразования, содержат до $72 \%$ ароматических соединений явно термогенного характера [8]. Растворимая часть ОВ отдельных образцов заметно различается по составу; битумоид исследовавшегося ранее [9] и так же глубоко превращенного верхнерифейского сланца валюхтинской свиты этого же региона содержал $83 \%$ гетероатомных соединений, среди которых преобладали свойственные сингенетичным битумоидам кислотные компоненты. 


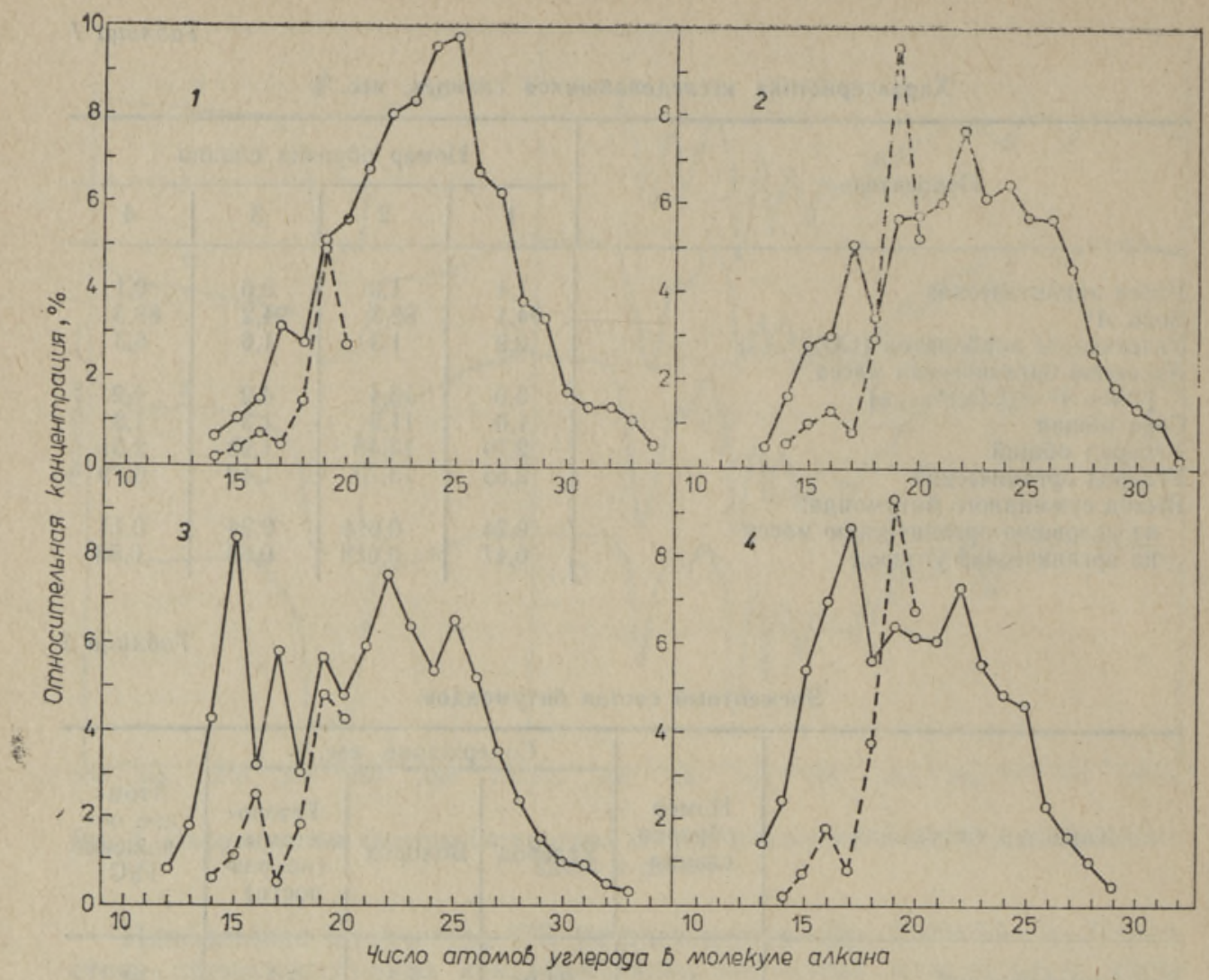

Рис. 2. Распределение по длине цепи $\boldsymbol{н}$-алканов (сплошная линия) и регулярных изопренондных алканов (пунктир) в битумондах. Концентрация дана относительно суммы алканов нормального и изопреноидного строения.

Судя по инфракрасным спектрам (рис. 1), в битумоидах доминюруют насыщенные структуры (сильное поглощение в областях 1460-1470, 1380 и $720 \mathrm{~cm}^{-1}$ ), что подтверждается очень высоким отношением H/C. Среди кислородсодержащих групп преобладают карбонильные (1710$\left.1740 \mathrm{~cm}^{-1}\right)$. В битумоиде обр. 1 можно предполагать присутствие фенольных гидроксильных групп (1350 и 1190-1200 см-1), в спектрах остальных экстрактов более выражены характерные для спиртовых гидроксилов полосы $(1290,1120$ и 1070-1080 см-1), хотя, по сравнению с карбонильными, гидроксильные группы обоих типов имеют явно подчиненное значение. Широкая полоса поглощения в области $2500-3500 \mathrm{~cm}^{-1}$ является признаком наличия карбоксильных групп; особенно это выражено в спектре битумоида обр. 2 и согласуется с данными о повышенном содержании в нем кислотных соединений (табл. 3).

Состав хроматографических фракций битумоидов, по адсорбционным свойствам соответствующих ароматическим УВ и содержащихся в небольшом количестве в экстрактах, очень сложный. Конденсированные ароматические УВ представлены соединениями с тремя и более циклами в молекуле, при этом, по-видимому, преобладают частично гидрированные соединения.

В составе $H$-алканов битумоидов видную роль играют соединения $\mathrm{C}_{18}-\mathrm{C}_{27}$ при невысоком коэффициенте нечетности (рис. 2, табл. 4). Вероятным их источником является бактериальная биопродукция $\left[{ }^{10,11}\right]$. В то же время можно допустить генерацию этих парафинов путем малоселективного термокаталитического ресинтеза (в том числе с удлине- 
Характеристика алифатических соединений битумоидов

\begin{tabular}{|c|c|c|c|c|}
\hline \multirow{2}{*}{ Показатель } & \multicolumn{4}{|c|}{ Номер образца сланца } \\
\hline & 1 & 2 & 3 & 4 \\
\hline Коэффициент нечетности н-алканов & 1,02 & 1,03 & 1,22 & 1,16 \\
\hline $\begin{array}{l}\text { Концентрационное отношение } \boldsymbol{t} \text {-алканов } \\
\left(\mathrm{C}_{12}-\mathrm{C}_{17}\right):\left(\mathrm{C}_{18}-\mathrm{C}_{34}\right)\end{array}$ & 0,08 & 0,20 & 0,40 & 0,52 \\
\hline $\begin{array}{l}\text { Содержание изопренондных алканов, вес. \%: } \\
\text { от общего содержания } \boldsymbol{H} \text {-алканов }\end{array}$ & 12,3 & 28,4 & 18,4 & 30,5 \\
\hline от содержания $H$-алканов $\mathrm{C}_{14}-\mathrm{C}_{20}$ & 57,3 & 81,2 & 44,6 & 56,4 \\
\hline Концентрационное отношение «пристан:фитан» & 1,82 & 1,83 & 1,15 & 1,37 \\
\hline $\begin{array}{l}\text { Концентрационное отношение изопреноидных } \\
\text { алканов }\left(\mathrm{C}_{14}-\mathrm{C}_{18}\right):\left(\mathrm{C}_{19}-\mathrm{C}_{20}\right)\end{array}$ & 0,39 & 0,47 & 0,73 & 0,45 \\
\hline $\begin{array}{l}\text { Коэффициент нечетности } \boldsymbol{H} \text {-алканонов-2 } \\
\text { К }\end{array}$ & 1,08 & . & 5,54 & 9,04 \\
\hline $\begin{array}{l}\text { Концентрационное отношение } H \text {-алканонов-2 } \\
\left(\mathrm{C}_{11}-\mathrm{C}_{17}\right):\left(\mathrm{C}_{18}-\mathrm{C}_{26}\right)\end{array}$ & 0,62 & - & 0,47 & 2,45 \\
\hline $\begin{array}{l}\text { Коэффищиент четности насыщенных алифатиче- } \\
\text { ских кислот нормального строения }\end{array}$ & 2,91 & 4,61 & 5,75 & 5,99 \\
\hline $\begin{array}{l}\text { Конщентрационное отношение жирных кислот } \\
\left(\mathrm{C}_{7}-\mathrm{C}_{15}\right):\left(\mathrm{C}_{16}-\mathrm{C}_{32}\right)\end{array}$ & 0,32 & 0,30 & 1,11 & 1,33 \\
\hline
\end{tabular}

нием цепи) из материала иного происхождения $\left[{ }^{12,13}\right]$. Ранее $\boldsymbol{H}$-алканы подобного состава были обнаружены в рифейских сланцах валюхтинской свиты Патомского региона [14], а также в архейских графитовых гнейсах Приазовья и кианитовых сланцах Кольского полуострова [15].

Однако следует подчеркнуть, что в битумоидах исследовавшихся сланцев содержится относительно много термически малоустойчивых изопреноидных алканов $\mathrm{C}_{14}-\mathrm{C}_{20} \quad(45-81 \%$ от количества н-алканов $\mathrm{C}_{14}-\mathrm{C}_{20}$ ), среди которых пристан преобладает над фитаном, что может рассматриваться как признак деградированности ОВ $\left[{ }^{16}\right]$. С другой стороны, это может быть обусловлено влиянием окислительной среды, в которой происходило формирование битумоидов $\left[{ }^{17}\right]$. Обогащение же УВ изопреноидами и другими изоалканами ** закономерно при бактериальном воздействии, когда прежде всего ассимилируются парафины нормального строения. Об отсутствии заметного термического воздействия на изопреноидные УВ в данном случае говорит и преобладание среди них высших, малодеградированных гомологов (табл. 4).

Трудно предположить, что содержащиеся в битумоидах насыщенные алифатические кислоты нормального строения являются продуктами природных термических процессов (рис. 3). Они имеют высокий коэффициент четности, представлены в основном распространенными в биосфере кислотами $\mathrm{C}_{12}-\mathrm{C}_{18}$ и мало отличаются от найденных в современных морских осадках $\left[{ }^{18,19}\right]$. Наряду с кислотами нормального строения в битумоидах содержится значительное количество изокислот, свойственных бактериальному ОВ [20]. Из непредельных кислот во всех образцах идентифицирована олеиновая, в незначительных количествах установлены дикарбоновые кислоты (обнаружены $\mathrm{C}_{8}-\mathrm{C}_{12}$ ). Считаем, что присутствующие в битумоидах сланцев кислоты представляют собой в основном инфильтрационные или ресинтезированные продукты.

Анализ материалов показывает, что во фракции нейтральных гетероатомных соединений битумоида обр. 2 алифатические кетоны отсутствуют. В соответствующей фракции экстракта из обр. 1 они имеют

** По данным газохроматографического анализа, во фракции неароматических УВ рассматрнваемых битумондов содержится много изосоединений, что отражается и в инфракрасных спектрах (интенсивное поглощение метильными группами). 


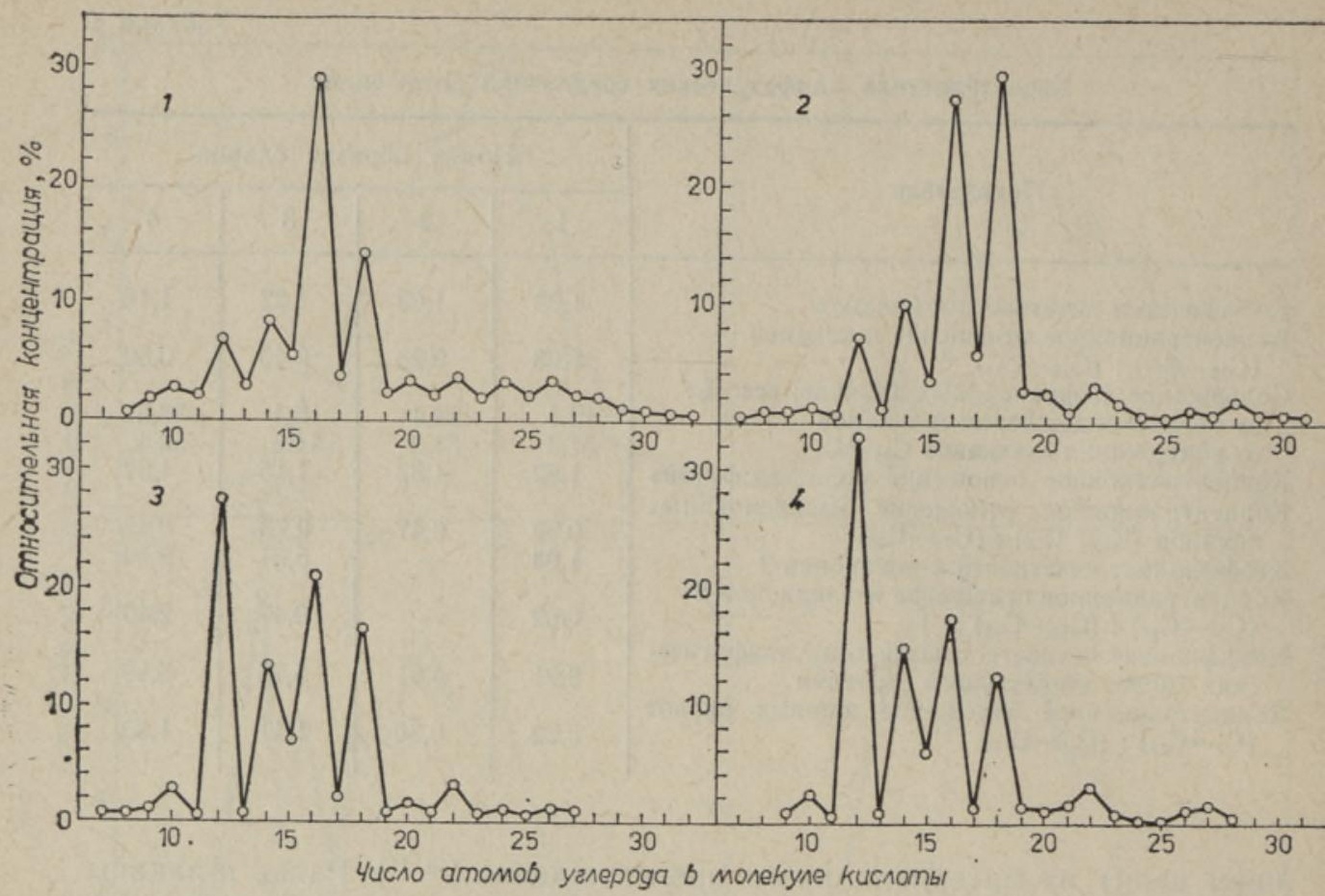

Рис. 3. Распределение по длине цепи насыщенных алифатических кислот нормального строения в битумоидах.

подчиненное значение (идентифицированы Среди кислородсодержащих соединений обр. 3 и 4 метил-н-алкилкетоны (также $\mathrm{C}_{11}-\mathrm{C}_{26}$ ) играют ведущую роль и отличаются высоким коэффициентом нечетности (табл. 4), что характерно для кетонов, образующихся при биосинтезе $\left.{ }^{21}\right]$. В обр. 3 кетоны $\mathrm{C}_{17}, \mathrm{C}_{19}$ и $\mathrm{C}_{21}$ составляют $69 \%$, а в обр. 4 на кетоны $\mathrm{C}_{11}, \mathrm{C}_{13}$ и $\mathrm{C}_{15}$ приходится $61 \%$ от всех идентифицированных $\mu$-алканонов-2. После интенсивного термического воздействия, нивелирующего особенности состава этой группы соединений, ее сохранение в настоящем виде малоправдоподобно. Важно также подчеркнуть, что несмотря на общую высокую степень катагенетической преобразованности пород, которая должна была привести к нивелированию состава $\mathrm{OB}$, в том числе и его растворимых компонентов, кислородсодержащие соединения изученных битумоидов существенно различаются между собой.

Для общей характеристики нерастворимой части ОВ сланцев (по выходу продуктов термического разложения) дебитумоидированные образцы подвергли полукоксованию. При проведении эксперимента в стандартной реторте смолы не были получены. В следовых количествах они выделялись лишь при использовании 10 -кратного количества сланца (500 г) и после обогащения породы смесью концентрированных соляной и плавиковой кислот. Основным продуктом термической деструкции являлся полукокс (выход для обр. 1-4 соответственно 98,1; 98,5; 96,4 и $99,6 \%$ на сухой дебитумоидированный сланец). В качестве летучих соединений выделялись вода и газ (в среднем соответственно 0,7 и 1,2\%). Следовательно, возможности нерастворимой части ОВ этих сланцев продуцировать при термолизе жидкие углеводородные компоненты практически полностью исчерпаны.

Судя по хроматограммам суммарных смол, экстрагированных в миллиграммовых количествах из подсмольных вод, в них содержатся 
н-алканы $\mathrm{C}_{12}-\mathrm{C}_{20}$, тогда как обычные для сланцевых смол $н$-алкены отсутствуют.

Газообразные продукты полукоксования состоят в основном из двуокиси углерода (для обр. $1-4$ соответственно $62,67,68$ и 91 об. \% в расчете на безвоздушный газ), подчиненное значение имеют УВ (соответственно $25,11,18$ и $2 \%)$, окись углерода $(13,11,14$ и $5 \%$ ) и сероводород (от следов до $3 \%$ ). Интересно, что продукты конечного этапа газообразования при катагенезе верхнепротерозойских отложений Сибири состоят также в основном из углекислого газа $\left[{ }^{22}\right]$.

В целом, согласно полученным данным, исследуемые битумоиды докембрийских сланцев не имеют почти ничего общего с основной массой графитоидного ОВ. Можно только предположить, что последнее явилось благоприятным субстратом для микроорганизмов, создавших в процессе своей жизнедеятельности присутствующий в настоящее время в сланце битумоид, который в процессе геохимического развития не подвергался существенным термическим преобразованиям.

Вышесказанное говорит о необходимости осторожного подхода к интерпретации данных анализа битумоидов древних пород в аспекте реконструкции состава былых биосфер.

\section{ЛИТ Е РАТ УРА}

1. Котлуков B. А. Горючие сланщы СССР и общие закономерности размещения их месторождений. - В кн.: Геология месторождений угля и горючих сланцев СССР, II. Горючие сланцы СССР. М., 1968, 7-11.

2. Горючие сланцы (под ред. Т. Ф. Иена и Дж. В. Чилингаряна). Л., 1980.

3. Аарна А. Я., Уров К. Э. О некоторых терминах в области горючих сланцев. Хим. тверд. топл., 1973, № 6, 149-151.

4. Klesment, I. Application of chromatographic methods in biogeochemical investigations. - J. Chromatogr., 1974, 91, N 2, 705-713.

5. Robinson, W. E. Isolation procedures for kerogens and associated soluble organic materials. - In: Organic Geochemistry. Methods and Results. Berlin, Heidelberg, New York, 1969, 181-195.

6. Неручев С. Г. Нефтепроизводящие свиты и миграция нефти. Л., 1969.

7. Уров К. Э. Сравнительная характеристика спиртобензольного и эфирного экстрактов керогена кукерсита. - Хим. тверд. топл., 1975, № 5, 66-67.

8. Клубов Б. А., Уров K. Э. Девонские горючие сланцы Селенняхского поднятия (Северо-Восточная Якутия). - Докл. АН СССР, 1979, 247, № 5, 1257-1260.

9. Дробот Д. И., Уров К. Э., Листрем А. И. Рассеянное органическое вещество верхнепротерозойских отложений Байкало-Патомского нагорья. - В кн.: Всесоюзное совещание «Геохимия горючих сланцев». Тезисы докладов. Таллин, 1978, $39-41$.

10. Middleditch, B. S., Basile, B. Alkanes in surficial sediments from the region of the Buccaneer oilfield. - J. Chromatogr., 1978, 158, N 5, 449-463.

11. Норенкова И. К., Архангельская Р. А., Тарасова Т. Г. Особенности химического состава водорастворенных органических веществ, синтезированных в процессе бнохимического окисления нефтей разного типа. - Геохимия, 1979, № 11, $1698-1707$.

12. Shimoyama, A., Johns, W. D. Formation of alkanes from fatty acids in the presence of $\mathrm{CaCO}_{3}$. - Geochim. et cosmochim. acta, 1972, 36, 87-91.

13. Гусева А. Н., Лейфман Н. Е. Генезис твердых углеводородов как подтверждение осадочно-миграционной природы нефти. - В кн.: Современные проблемы геологии и геохимии горючих ископаемых. М., 1973, 88-93.

14. Уров К. Э., Клесмент Н. Р. Сравнительная геохимическая характеристика органического вещества докембрийских и нижнепалеозойских сланщев. - Геохимия, 1979, № 11, 1679-1686.

15. Сидоренко Св. А., Сидоренко А. В. Органическое вещество в осадочно-метаморфических породах докембрня. М., 1975.

16. Шляхов $A$. Ф., Волкова Л. Г. Стереохимия изопренондных алканов и возможные пути их образования в осадочных породах. - Геохимия, 1977, № 9, 14181423.

17. Philp, R. P., Brown, S., Calvin, M. Isoprenoid hydrocarbons produced by thermal alternation of Nostoc muscorum and Rhodopseudomonas spheroides. - Geochim. et cosmochim. acta, 1978, 42, 63-68. 
18. Simoneit, B. R. T. Diterpenoid compounds and other lipids in deep-sea sediments and their geochemical significance. - Geochim, et cosmochim. acta, 1977, 41, $463-476$.

19. Volkman, J. K., Johns, R. B., Gillan, F. T., Perry, G. J. Microbial lipids of an intertidal sediment. I. Fatty acids and hydrocarbons. - Geochim. et cosmochim. acta, 1980, 44, 1133-1143.

20. Johnson, R. W., Calder, J. A. Early diagenesis of fatty acids and hydrocarbons in a salt marsh environment. - Geochim. et cosmochim. acta, 1973, 37, 1943-1955.

21. Eglinton, O., Hamilton, R. Leaf epicuticular waxes. - Science, 1967, 156, N 3780, $1322-1335$.

22. Дробот Д. И. Органическое вещество докембрийских и нижнекембрийских отложений юга Сибирской платформы и его роль в процессах нефте- и газообразования. - В кн.: Тезисы 5-го Всесоюзного семинара «Органическое вещество в современных и ископаемых осадках». М., 1976, 179-180.
Ннститут химии
Академии наук Әстонской ССР
Поступила в редакцию

Восточно-Сибирский научно-исследовательский институт

геологии, геофизики и минерального сырья (Иркутск)

K. UROV, V. VOSSOTSKAJA, D. DROBOT

\section{ENDISTE POLEVKIVIDE (IDA-SIBERI VANADE GRAFITISEERUNUD KILTADE) ORGAANILISE AINE UURIMINE}

Ida-Siberi rifeuse-vendi moondunud kiltkivide grafitoidse orgaanilise aine potentsiaalsed võimalused produtseerida termilisel lagunemisel vedelaid orgaanilisi produkte on praktiliselt ammendatud. Uuritud kivimite bitumoidide (nende süsinikusisaldus on $0,44 \%$ kivimi orgaanilise aine süsinikust) koosseisus aga on bioloogilise lähtematerjali keemiline omapära väga hästi säilinud. Oletatakse, et bitumoidi ja orgaanilise aine lahustamatu osa allikad ja kujunemisteed olid erinevad, seetōttu ei tohi vanades kivides sisalduva lahustuva orgaanilise aine koostise põhjal teha kaugeleulatuvaid järeldusi kogu tolle aja orgaanilise aine kohta.

\section{K. UROV, V. VYSSOTSKAYA, D. DROBOT}

\section{INVESTIGATION OF THE ORGANIC MATTER OF FORMER OIL SHALES (ANCIENT GRAPHITIZED SHALES OF EASTERN SIBERIA)}

The ability of the graphitized organic matter of highly metamorphosed Proterozoic shales of Irkutsk Region to produce liquid organic products on thermal decomposition is practically exhausted. In the composition of bitumens of the shales under study (average content $0.44 \%$ on organic carbon), the chemical features of the initial biological material have been especially well preserved. The ways of formation of bitumen and insoluble part of the shales organic matter are supposed to have been different. For that reason it is necessary to be cautious in defining the nature of long past biospheres when interpreting data on the chemical composition of the extractable part of the organic matter of Pre-Cambrian shales. 